www.volsu.ru

DOI: https://doi.org/10.15688/jvolsu3.2019.2.2

UDC 330.34

Submitted: 12.04.2019

LBC 65.05

Accepted: 30.04 .2019

\title{
THE ANALYSIS OF THE FINANCIAL SECURITY OF RUSSIA: CURRENT TRENDS, CHALLENGES, THREATS ${ }^{1}$
}

\author{
Marina E. Buyanova \\ Volgograd State University, Volgograd, Russian Federation \\ Yevgeniy S. Rasskazov \\ Volgograd State University, Volgograd, Russian Federation
}

\begin{abstract}
Financial security is one of the main factors of competitive and sustainable development of any country in the world. In addition, financial security is an integral part of national security of any state and, from the practical point of view, it represents a special condition of the national financial system described by the system of special criteria. Current confrontation on the global stage sets the particularly acute task of improving national financial security and the security of the entire economy in the face of modern threats manifesting in sanctions. In order to understand which sectors of the economy are the most vulnerable, it is necessary to compute special indicators that can characterize the state of the national financial security. The system of criteria for assessing the national financial security developed within the framework of the methodology proposed by Russian scientistseconomists V.K. Senchagov, G.N. Maltsev, I.G. Maltseva is the most complete and widely used in Russia and includes the in-depth system of 40 indicators grouped into 5 systemic blocks. This system of indicators served as a methodological basis of the authors' calculations in the article. In addition, this study analyzed the main problems of the Russian economy identified after the calculations, as well as compared them with those identified in the official forecasts and development strategies.
\end{abstract}

Kew words: financial security, state, indicators, vulnerability, threats.

Citation. Buyanova M.E., Rasskazov Ye.S. The Analysis of the Financial Security of Russia: Current Trends, Challenges, Threats. Vestnik Volgogradskogo gosudarstvennogo universiteta. Seriya 3, Ekonomika. Ekologiya [Science Journal of Volgograd State University. Global Economic System], 2019, vol. 21, no. 2, pp. 19-33. (in Russian). DOI: https://doi.org/10.15688/jvolsu3.2019.2.2

УДК 330.34

Дата поступления статьи: 12.04.2019

ББК 65.05

Дата принятия статьи: 30.04.2019

\section{АНАЛИЗ ФИНАНСОВОЙ БЕЗОПАСНОСТИ РОССИИ: СОВРЕМЕННЫЕ ТЕНДЕНЦИИ, ВЫЗОВЫ, УГРОЗЫ ${ }^{1}$}

\author{
Марина Эдуардовна Буянова \\ Волгоградский государственный университет, г. Волгоград, Российская Федерация \\ Евгений Сергеевич Рассказов \\ Волгоградский государственный университет, г. Волгоград, Российская Федерация
}

\begin{abstract}
Аннотация. Финансовая безопасность является одним из основных факторов конкурентоспособного и устойчивого развития любой страны. В дополнение к этому финансовая безопасность выступает неотъемлемой частью национальной безопасности государства и с практической точки зрения представляет собой особое состояние национальной финансовой системы, описываемой с помощью системы специальных критериев. В современных условиях конфронтации на мировой арене особенно остро встает проблема повышения финансовой безопасности государства и увеличения защищенности экономики перед современными угроза-
\end{abstract}


ми, носящими санкционный характер. Для того чтобы понять, какие отрасли хозяйства являются наиболее уязвимыми, необходимо рассчитать специальные показатели, которые способны охарактеризовать состояние финансовой безопасности государства. Наиболее полная и широко используемая в России система критериев финансовой безопасности государства разработана в рамках методики, предложенной российскими учеными-экономистами В.К. Сенчаговым, Г.Н. Мальцевым, И.Г. Мальцевой и включающей емкую систему из 40 индикаторов, сгруппированных в 5 системных блоков. Именно эта система показателей составила методическую основу авторских расчетных и оценок, результатом которых стало обоснование современных тенденций, вызовов и угроз финансовой безопасности. Кроме того, в данном исследовании были проанализированы основные проблемы экономики, выявленные после проведения расчетов, а также проведено их сравнение с теми, которые обозначены в официальных прогнозах и стратегиях развития.

Ключевые слова: финансовая безопасность, государство, индикаторы, уязвимость, угрозы.

Цитирование. Буянова М. Э., Рассказов Е. С. Анализ финансовой безопасности России: современные тенденции, вызовы, угрозы // Вестник Волгоградского государственного университета. Серия 3, Экономика. Экология. - 2019. - Т. 21, № 2. - C. 19-33. - DOI: https://doi.org/10.15688/jvolsu3.2019.2.2

\section{Введение}

В современных условиях глобализации и взаимосвязанности экономик мира перед всеми государствами встает вопрос обеспечения такого уровня финансовой безопасности страны, который позволит устранить проблематичность определенных сегментов хозяйства и модернизировать его в целом. Каждое государство подвержено как внутренним, так и внешним угрозам и рискам, имеющим различную природу - экономическую, финансовую, политическую, экологическую и др. Для того чтобы выявить данные угрозы и разработать комплекс мер, направленный на элиминацию или сужение их потенциального воздействия, необходимо обратиться к определенному расчетному аппарату, который позволит оценить основные сферы экономической деятельности с позиции финансовой безопасности.

В силу разнообразия и масштаба проявления вызовов и угроз, такого рода оценка основана на использовании специфических научных и методических подходов и достаточно большого и разнообразного набора показателей, позволяющих оценить количественные изменения в уровне финансовой безопасности.

Стратегией экономической безопасности России до 2030 г. утверждены 40 показателей, которые необходимо мониторить для оценки состояния экономической безопасности и ее составляющих элементов. Среди основных угроз развития национальной экономики выделены, в частности, и угрозы, определяющие финансовую безопасность страны: рост частной и суверенной задолженности; разрыв меж- ду стоимостной оценкой реальных активов и производственных ценных бумаг; ограничения доступа к международным финансовым ресурсам и современным технологиям; колебания на мировых товарных и финансовых рынках; уязвимость финансово-банковской системы [Указ Президента от 13.05.2017 № 208 ...].

Поскольку одним из критериев, отвечающих требованиям экономической безопасности России, является устойчивость финансовой системы, то, следовательно, показатели, ее характеризующие, могут служить индикаторами оценки уровня финансовой безопасности страны. К ним относятся показатели состояния федерального бюджета, банковской и денежной системы, денежного обращения, а также развития финансового рынка и рынка ценных бумаг. Кроме того, индикаторы состояния финансовой безопасности необходимо оценивать в сравнении с количественными параметрами пороговых значений, то есть параметров, нарушение которых будет означать вход в опасную зону, нарушение нормального хода экономики, ее незащищенность от внешних негативных воздействий. Институт экономики РАН с периодичностью в 4-5 лет разрабатывает и уточняет эти пороговые значения, но они не были одобрены или утверждены каким-либо государственным органом и не использовались в текущей деятельности государства. В качестве показателей, близких по своему статусу к утвержденным пороговым значениям, должны быть использованы также показатели, содержащиеся, например, в указах Президента России или в выступлениях руководства страны (например, в 
М.Э. Буянова, Е.С. Рассказов. Анализ финансовой безопасности России

посланиях Федеральному собранию). Это целевые показатели, отражающие экономическую политику государства и его национальные интересы в области экономики [Сенчагов и др., 2015].

Одной из методик определения финансовой безопасности государства является методика В.К. Сенчагова, Г.Н. Мальцева, И.Г. Мальцевой, которая включает 40 индикаторов оценки экономико-финансовой защищенности страны [Сенчагов и др., 2015]. Обратимся к некоторым из них и выявим, какие основные проблемы наличествуют в экономике России [Экономическая безопасность ..., 2015].

\section{Результаты и обсуждение}

В первую категорию показателей данной методики включены макроэкономические индикаторы, которые разбиты на 4 подгруппы. В первую подгруппу входят индикаторы, отражающие состояние государственного бюджета, позволяющие оценить уровень дефицита и государственного долга по отношению к внутреннему валовому продукту (далее - ВВП), а также долю расходов на обслуживание государственного долга в общих расходах правительства (рис. 1, 2).

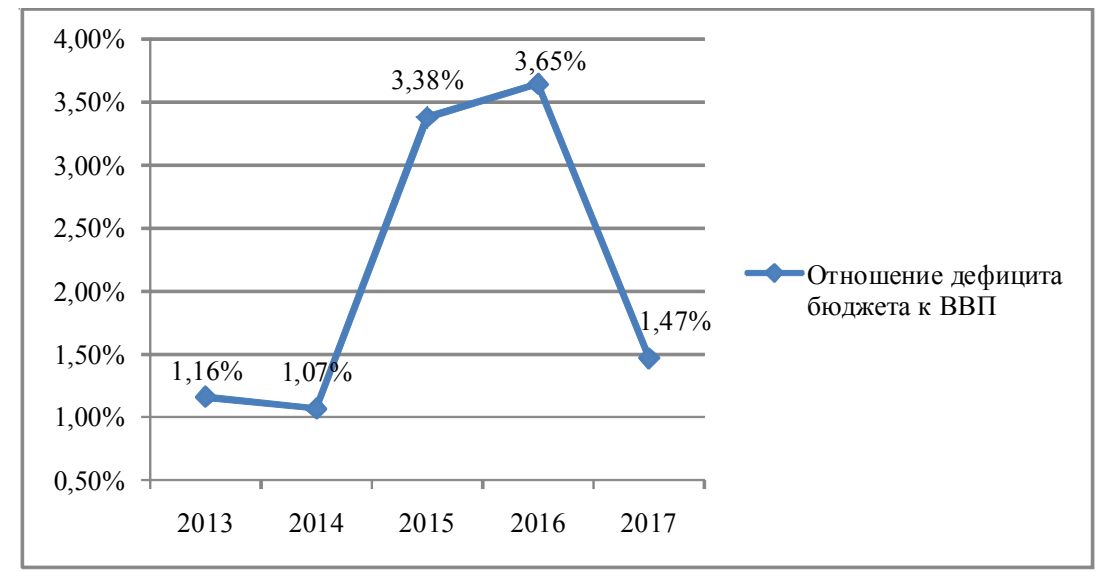

Рис. 1. Отношение дефицита бюджета России к ВВП, \%

Примечание. Составлено авторами по: [Консолидированный бюджет ...; Н Национальные счета ...].

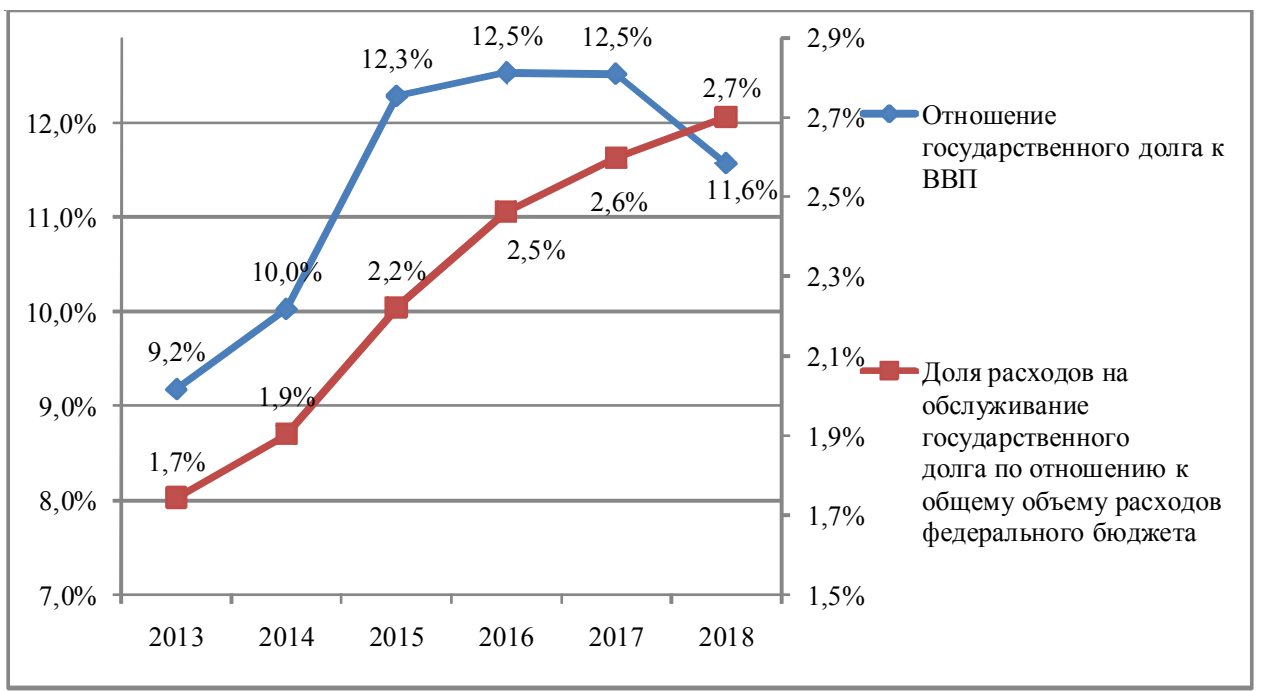

Рис. 2. Отношение государственного долга к ВВП и доля расходов на обслуживание государственного долга по отношению к общему объему расходов федерального бюджета, \%

Примечание. Составлено авторами по: [Консолидированный бюджет ... ; Национальные счета ...; Объем государственного внешнего долга ... ; Объем государственного внутреннего долга ...]. 


\section{ЭКОНОМИЧЕСКАЯ ТЕОРИЯ}

Как видно из представленного графика (см. рис. 1), показатель «отношение дефицита бюджета России к ВВП» в 2015 и 2016 гг. выходил за пороговую границу (пороговое значение для данного показателя - 3 \%) ввиду ряда причин, основной из которых является снижение нефтегазовых доходов бюджета в связи с падением мировых цен на нефть, нивелировавшее повышение ненефтегазовых доходов. В 2017 г. абсолютный прирост бюджетных доходов превысил абсолютный прирост бюджетных расходов более чем в 2,5 раза, что в конечном счете вернуло индикатор в зону нормальных значений.

На протяжении 2013-2017 гг. государственный долг РФ продолжал увеличиваться (см. рис. 2), при этом стоит отметить, что данное увеличение происходило более быстрыми темпами, нежели наращивание ВВП. В итоге доля государственного долга России в ВВП возросла с 9,2 \% до 12,5\%. Тем не менее данная тенденция переломилась в 2018 г., когда ВВП страны обогнал по темпам роста государственный долг, что выразилось в уменьшении индикатора. Тренд 2013-2017 гг., в свою очередь, вызвал и увеличение расходов на обслуживание накопившегося государственного долга в структуре расходов бюджета. Однако пороговые значения для представленных индикаторов - 60 \% и $20 \%$ соответственно, поэтому наблюдаемый показатель все еще находится в нормальной зоне. Более того, внешний государственный долг в долларовом выражении начал свое снижение с 2015 г., однако из-за флуктуаций курса доллар / рубль его изменение в рублевом выражении было иным.

Далее рассмотрим показатели, отражающие уровень долговой нагрузки нефинансовых предприятий и банковских организаций. Вначале обратимся к отношению долга нефинансовых предприятий к их выручке (рис. 3).

За весь анализируемый период времени данный индикатор находился за границей порогового значения, превышая ее более чем в два раза, что говорит о высокой закредитованности нефинансового сектора российской экономики и наличии проблем с оплатой обязательств перед поставщиками и подрядчиками. В целом и краткосрочная, и долгосрочная задолженности выросли за 5 лет более чем на $60 \%$. С 2015 г. наметилась тенденция на снижение доли задолженности в выручке нефинансовых предприятий - главным образом за счет более быстрых темпов прироста выручки, чем задолженности (см. рис. 3). Всплеск задолженности относительно выручки в 2015 г. также можно объяснить повысившейся ключевой ставкой, что увеличило и ставки по кредитам.

Далее рассмотрим структуру задолженности нефинансовых организаций во временном разрезе (см. рис. 4).

В рамках рассматриваемой методики соотношение для кратко- и долгосрочной задолженности нефинансовых предприятий должно быть равным 30/70. В течение 2013-

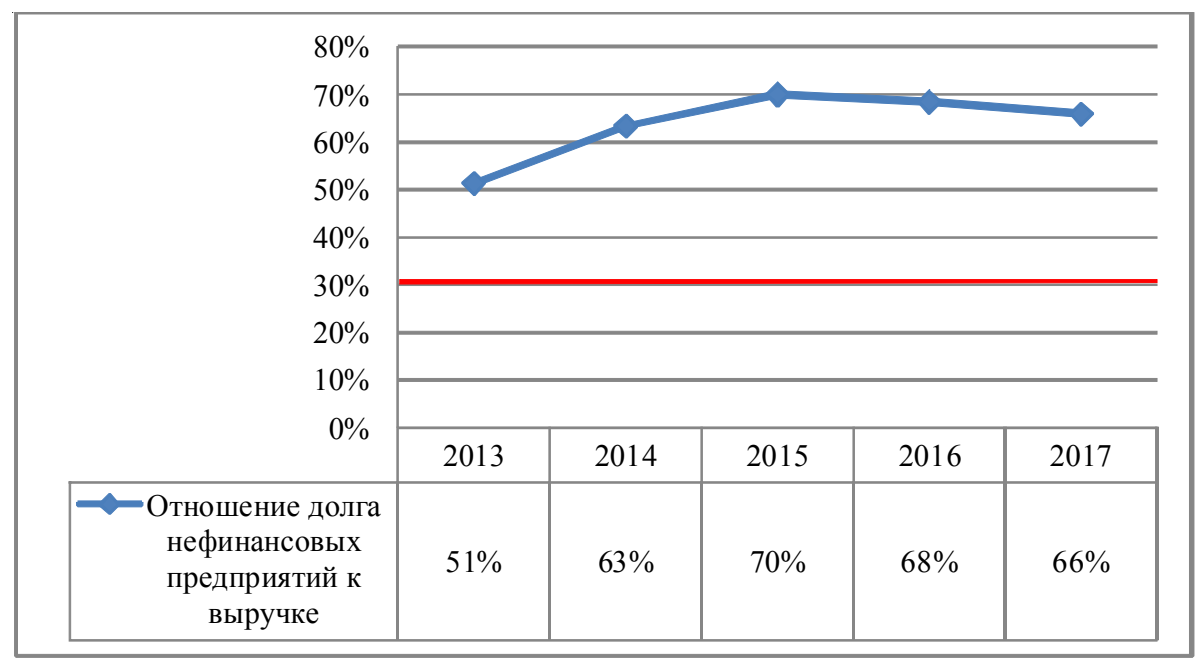

Рис. 3. Отношение долга нефинансовых предприятий к выручке, \%

Примечание. Составлено авторами по: [Финансы России, 2016; Финансы России, 2018]. 
М.Э. Буянова, Е.С. Рассказов. Анализ финансовой безопасности России

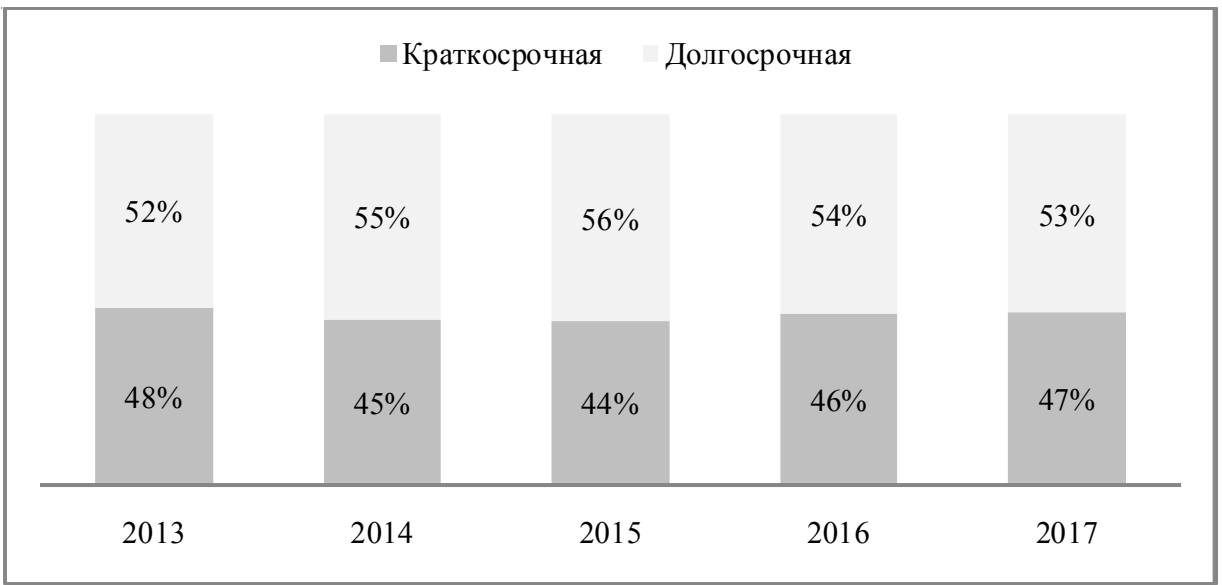

Рис. 4. Структура долга нефинансовых предприятий, \%

Примечание. Составлено авторами по: [Финансы России, 2016; Финансы России, 2018].

2017 гг. соотношение в среднем оставалось на уровне $45 / 55$. Перекос пороговой структуры задолженности в сторону краткосрочной говорит о том, что в структуре долгов немалую долю составляет кредиторская задолженность (задолженность перед поставщиками и подрядчиками, персоналом, по налогам и сборам и пр.). Сохранение данной тенденции создает потенциальную опасность дефолта компаний или возникновения кредитной ловушки, к тому же не стоит забывать о том, что долги нефинансовых компаний в среднем за тот же период составляли чуть более $60 \%$ при норме «менее $30 \%$ \%. Большая часть краткосрочной задолженности приходится на обрабатывающие производства, строительство, оптовую и розничную торговлю, профессиональную, на- учную и техническую деятельность, транспортировку и хранение.

После рассмотрения нефинансовых предприятий перейдем к анализу внешних долгов банковского сектора (рис. 5).

В отличие от нефинансовых организаций задолженность банковского сектора за весь рассматриваемый период оставалась ниже порогового значения в $30 \%$. Более того, за период 2013-2018 гг. она снизилась с 13 до $8 \%$. Это говорит о том, что российские банки все меньше полагаются на иностранные заемные средства. Сама задолженность в долларовом выражении методично снижалась с 2013 г. и уменьшилась к июлю 2018 г. в два раза.

Временная структура внешнего долга банковского сектора представлена на рисунке 6.

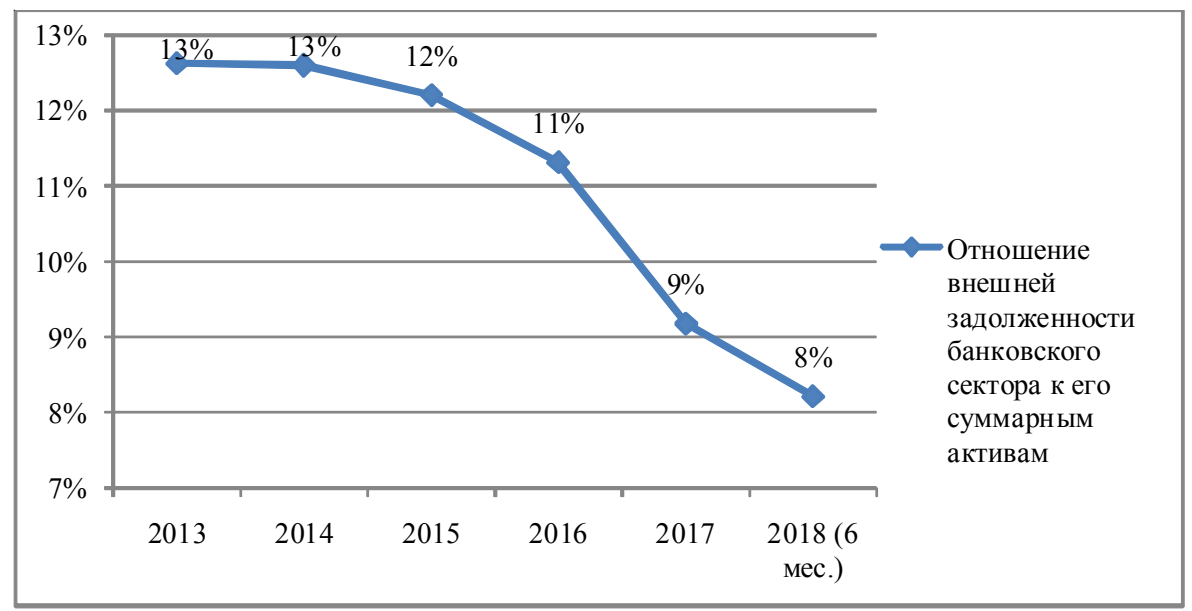

Рис. 5. Отношение внешней задолженности банковского сектора к его суммарным активам, \% Примечание. Составлено авторами по: [Отчет ... в 2017 г.; Прогноз ... до 2030 г.]. 


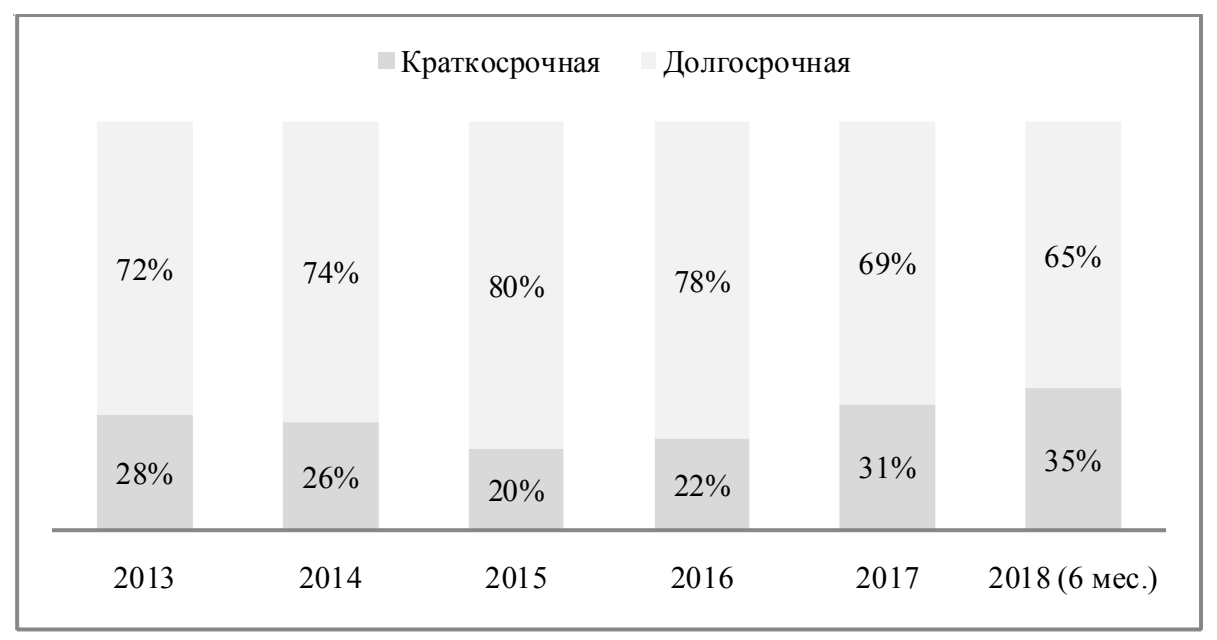

Рис. 6 . Соотношение кратко- и долгосрочной задолженности банков, \%

Примечание. Составлено авторами по: [Отчет ... в 2017 г.; Прогноз ... до 2030 г.].

В целом у организаций банковского сектора соотношение кратко- и долгосрочных долгов 30/70 соблюдается в гораздо большей степени, чем у нефинансовых предприятий. Тем не менее с 2016 г. у банков наметилась тенденция на повышение краткосрочной задолженности в общем объеме долгов, что потенциально может быть связано с переходом некоторой части задолженности из долгосрочной в краткосрочную в связи с приближающейся экспирацией ранее взятых займов.

Рассмотрим последний блок макроэкономических индикаторов - показатели макрофинансовых условий функционирования экономики (табл. 1).

Расчетные данные свидетельствуют о том, что в последние годы наметилась явная тенденция на усиление монетизации экономики. Иначе говоря, в 2013-2018 гг. российский това- рооборот был в достаточной мере обеспечен денежными ресурсами. Однако данный показатель в последние годы был подвержен незначительным флуктуациям из-за несбалансированности прироста ВВП и денежной массы. Кроме того, по сравнению с развитыми зарубежными странами, где этот показатель составляет 80$100 \%$ к ВВП, в российской экономике он недостаточно высок. При такой низкой степени насыщенности экономики денежной массой она не может нормально развиваться. Низкая монетизация экономика вызвала кроме недофинансирования развития низкую ликвидность банков, грозящую банковским кризисом и кризисом системы страхования вкладов.

Соблюдение второго критерия говорит об отсутствии чрезмерной кредитной экспансии в экономике. Третий индикатор вышел за пределы прироста в 50 \% лишь в декабре 2014 г.,

Таблица 1

Индикаторы макрофинансовых условий функционирования экономики

\begin{tabular}{|c|l|c|c|c|c|c|c|c|}
\hline $\begin{array}{c}\text { № } \\
\text { п/п }\end{array}$ & \multicolumn{1}{|c|}{ Индикатор } & $\begin{array}{l}\text { Пороговое } \\
\text { значение }\end{array}$ & 2013 г. & 2014 г. & 2015 г. & 2016 г. & 2017 г. & 2018 г. \\
\hline 1 & $\begin{array}{l}\text { Уровень монетизации экономики } \\
\text { (М2 в \% к ВВП) }\end{array}$ & $>20-30 \%$ & 37,1 & 39,3 & 37,9 & 40,8 & 41,7 & 40,9 \\
\hline 2 & $\begin{array}{l}\text { Индикатор изменения объема и } \\
\text { структуры денежного спроса и } \\
\text { предложения в экономике }\end{array}$ & ТпрМ2 <inf +10\% & + & + & + & + & + & + \\
\hline 3 & $\begin{array}{l}\text { Критический уровень изменения } \\
\text { реальной процентной ставки по } \\
\text { кредитным ресурсам и по депозитам }\end{array}$ & $\Delta \mathrm{r} / \mathrm{r}<50 \%$ & $\mathrm{n} / \mathrm{a}$ & $\begin{array}{c}\text { Де- } \\
\text { кабрь }\end{array}$ & + & + & + & + \\
\hline 4 & Рентабельность экономики & $\mathrm{P}>\inf$ & - & - & - & + & + & $\mathrm{n} / \mathrm{a}$ \\
\hline
\end{tabular}

Примечание. Составлено авторами по: [Национальные счета ... ; Процентные ставки ...; Финансы России, 2016; Финансы России, 2018]. 
когда Банк России повысил ключевую ставку до $17 \%$, что автоматически привело к росту реальной ставки по кредитам и депозитам и вызвало шоковую реакцию на рынке кредитования [Консолидированный бюджет ...]. Поскольку в рассматриваемой методике не был указан способ расчета данного показателя, рентабельность экономики рассчитывалась исходя из рентабельности продаж нефинансового сектора. Таким образом, оказалось, что рентабельность российской экономики не превышала инфляцию вплоть до 2016 г., чему главным образом способствовала разогнавшаяся в 2014 г. инфляция. Несмотря на соблюдение критерия в 2017 г., рентабельность продаж нефинансового сектора упала с 9,9\% до 7,3 \% по сравнению с 2016 г., что было вызвано возросшими издержками.

Рассмотрим следующую группу индикаторов, характеризующих соотношение сбережений и инвестиций в экономике.

На протяжении всего исследуемого периода времени сбережения превосходили инвестиции в экономику. В первую очередь это может говорить о неуверенности внутренних и внешних инвесторов в стабильности российской экономики, что в итоге и вызвало отставание инвестиций от сбережений. Также недостаточный прирост инвестиций может быть связан с повышением кредитных ставок с декабря 2014 г., что сделало кредитные ресурсы более дорогими и, соответственно, менее доступными. Для более подробного анализа сложившейся ситуации перейдем к рассмотрению инвестиций в основной капитал и недоиспользования сбережений для капитальных вложений (рис. 7).

В целом за 2013-2017 гг. инвестиции в основной капитал упали с 18,4 \% до 17,3 \%, однако в течение данного периода мы можем наблюдать перелом тенденции на снижение капитальных вложений в сторону их увеличения. Что касается недоиспользования сбережений, то здесь тенденция прямо противоположная, что вполне закономерно, ведь в экономике сбережения трансформируются в инвестиции. В используемой методике первый показатель не должен быть меньше $25 \%$, а второй - не более $30 \%$. Если второй индикатор укладывается в заданные рамки, то первый значительно отстает от него. Недостаток инвестиций в основной капитал при уже достаточно высоких процентах его износа у российских компаний способен в будущем неблагоприятно отразиться на экономическом росте страны.

Для того чтобы узнать об ожиданиях российских вкладчиков относительно стабильности национальной валюты, рассмотрим структуру национальных сбережений (см. рис. 8).

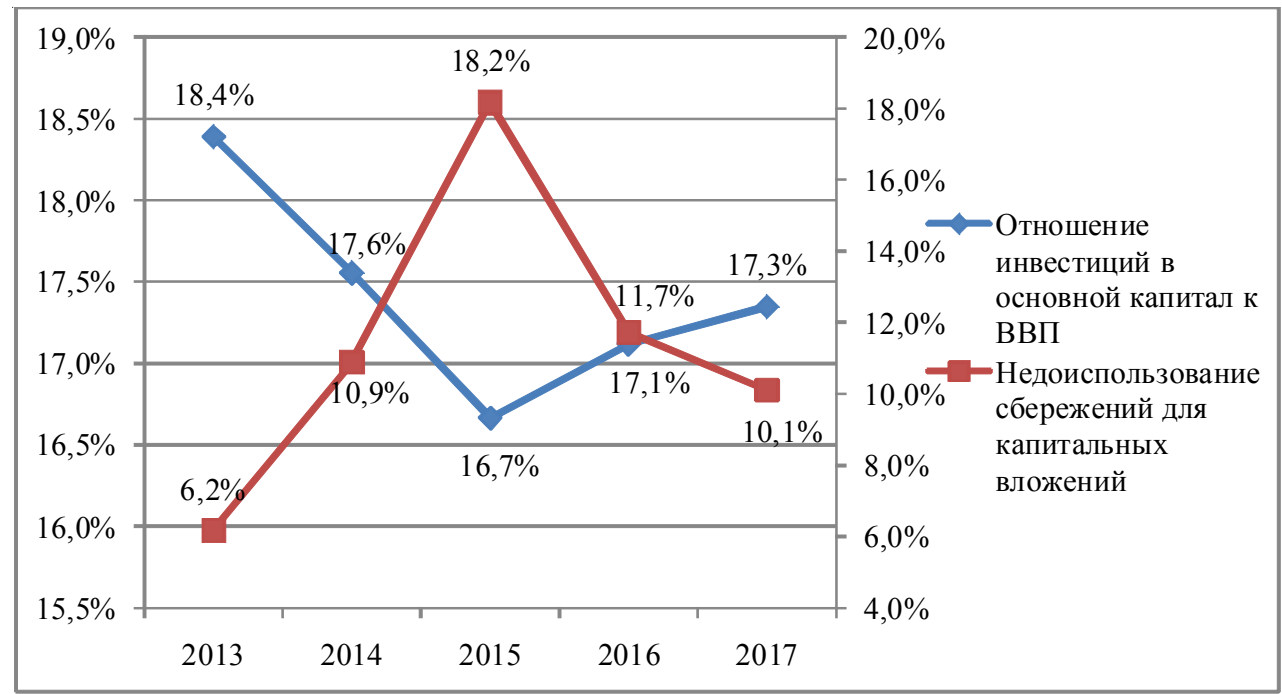

Рис. 7. Индикаторы отношения инвестиций в основной капитал к ВВП и недоиспользования сбережений для капитальных вложений, \%

Примечание. Составлено авторами по: [Национальные счета ... ; Информация по привлеченным ... ; Информация по размещенным ... ; Gross capital formation; Gross savings]. 


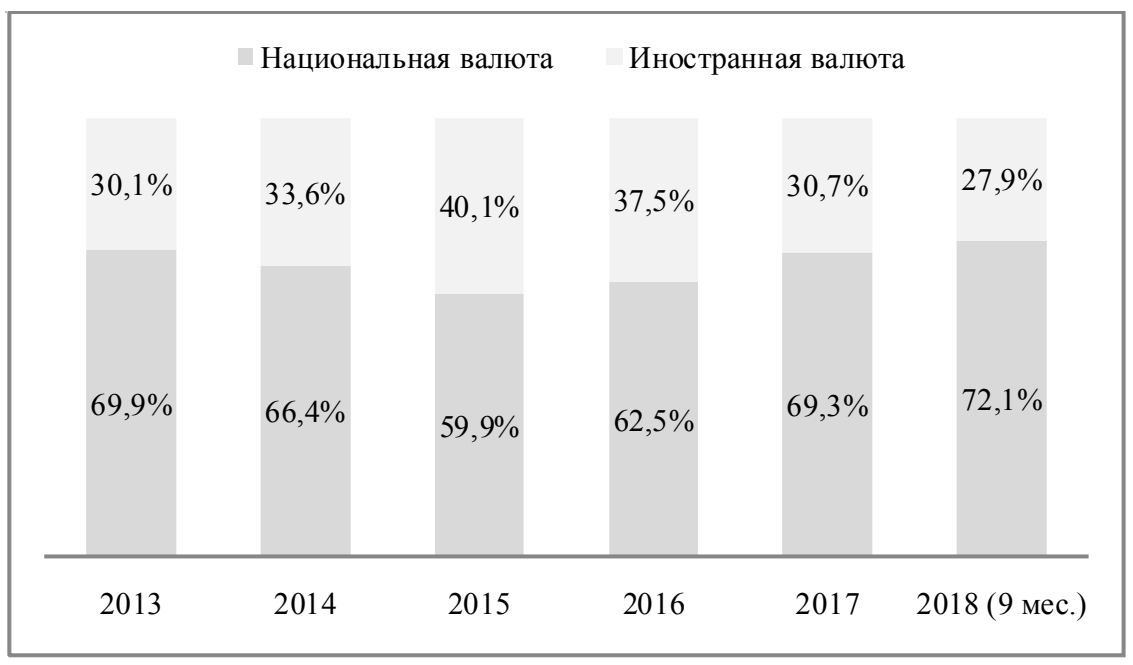

Рис. 8. Структура сбережений в национальной и иностранной валюте, \%

Примечание. Составлено авторами по: [Информация по привлеченным ...].

Несмотря на некоторый перекос в сторону вкладов в иностранной валюте в 20152016 гг., что, вероятнее всего, было связано с ослабляющимся рублем, в последние годы структура российский сбережений в национальной и иностранной валюте вернулась к соотношению 70/30 соответственно.

Теперь перейдем к оценке параметров привлеченных и размещенных средств банков (табл. 2).

Что касается сроков привлечения и размещения, то они не совпадали ни в одном году. По вкладам в иностранной валюте физические лица предпочитали сроки в 1-3 года, однако по рублевым вкладам до конца 2015 г. они вкладывались в депозитные продукты сроком от 1 до 3 лет, однако затем среди них стали более востребо- ванными и вклады со сроком от 181 дня до 1 года. Среди юридических лиц были более востребованы валютные депозиты со сроком выше 3 лет, а вот сроки по рублевым вкладам были более сглажены, тем не менее все же наблюдалось преобладание вкладов со сроками до 30 дней и от 31 до 90 дней. Статистика по размещенным средствам разбита по срокам только для организаций (за исключением кредитных), и они в основном предпочитали кредиты на срок более 3 лет как в рублевом, так и в инвалютном выражении. В индикаторе временной структуры были рассмотрены только депозиты, потому что только по ним предоставлена полная статистика с включением разбивки по всем субъектам (физическим лицам, юридическим лицам без КО, кредитным организациям и ИП). В рассмат-

Таблица 2

Параметры привлеченных и размещенных средств банков

\begin{tabular}{|c|c|c|c|c|c|c|c|c|}
\hline \begin{tabular}{|l} 
№ \\
П/ח \\
\end{tabular} & Параметр & $\begin{array}{c}\text { Пороговое } \\
\text { значение }\end{array}$ & 2013 г. & 2014 г. & 2015 г. & 2016 г. & 2017 г. & $\begin{array}{l}2018 \text { г. } \\
(9 \text { мес.) }\end{array}$ \\
\hline 1 & $\begin{array}{l}\text { Средние сроки привлечения и } \\
\text { размещения средств }\end{array}$ & $\begin{array}{c}\text { Примерное } \\
\text { равенство } \\
\text { сроков }\end{array}$ & - & - & - & - & - & - \\
\hline \multirow[t]{2}{*}{2} & \multirow[t]{2}{*}{$\begin{array}{l}\text { Временная структура кредитов } \\
\text { и депозитов }\end{array}$} & $\begin{array}{c}\text { До } 1 \text { года } \\
(30 \%)\end{array}$ & $35,3 \%$ & $35,1 \%$ & $44,7 \%$ & $42,7 \%$ & $45,0 \%$ & $50,8 \%$ \\
\hline & & $\begin{array}{c}\text { Более } 1 \text { года } \\
(70 \%)\end{array}$ & $64,7 \%$ & $64,9 \%$ & $55,3 \%$ & $57,3 \%$ & $55,0 \%$ & $49,2 \%$ \\
\hline 3 & $\begin{array}{l}\text { Отношение иностранной сово- } \\
\text { купной банковской позиции к } \\
\text { совокупному собственному ка- } \\
\text { питалу банковской системы }\end{array}$ & $<20 \%$ & $13 \%$ & $19 \%$ & $13 \%$ & $14 \%$ & $16 \%$ & $23 \%$ \\
\hline
\end{tabular}

Примечание. Составлено авторами по: [Информация по привлеченным ... ; Информация по размещенным ...; П Показатели деятельности ...]. 
риваемой методике эталонная временная структура в большей или меньшей степени соблюдалась в 2013 и 2014 гг., но затем стала смещаться к соотношению 50/50. Данная тенденция является негативной для банковского сектора и, несмотря на прирост объема депозитов, оставляет меньше маневров для наращивания кредитного портфеля и, соответственно, инвестирования в реальный сектор экономики. Последний индикатор превысил свое пороговое значение лишь в 2018 г., что было вызвано более быстрыми темпами прироста иностранных пассивов по сравнению с иностранными активами.

Далее рассмотрим долю кредитного портфеля банков в их активах, а также долю «плохих» долгов (рис. 9).

На протяжении всего изучаемого периода первый индикатор превосходил свое поро- говое значение в $45 \%$, а второй был меньше $10 \%$, что соответствует критериям финансовой безопасности. Несмотря на это, наблюдается негативная тенденция на снижение доли кредитного портфеля в активах банков и увеличение доли «плохих» кредитов (см. рис. 9). Первое говорит о возможном сдвиге банковских операций в сторону иностранных и спекулятивных операций. Второе подразумевает, что защищенность российского банковского сектора перед потенциальными кризисными явлениями становится все более слабой.

Завершают блок индикаторов безопасности банковской деятельности показатели рентабельности капитала и активов, степень зависимости банков от межбанковских кредитов и уровень концентрации банковской системы (табл. 3).

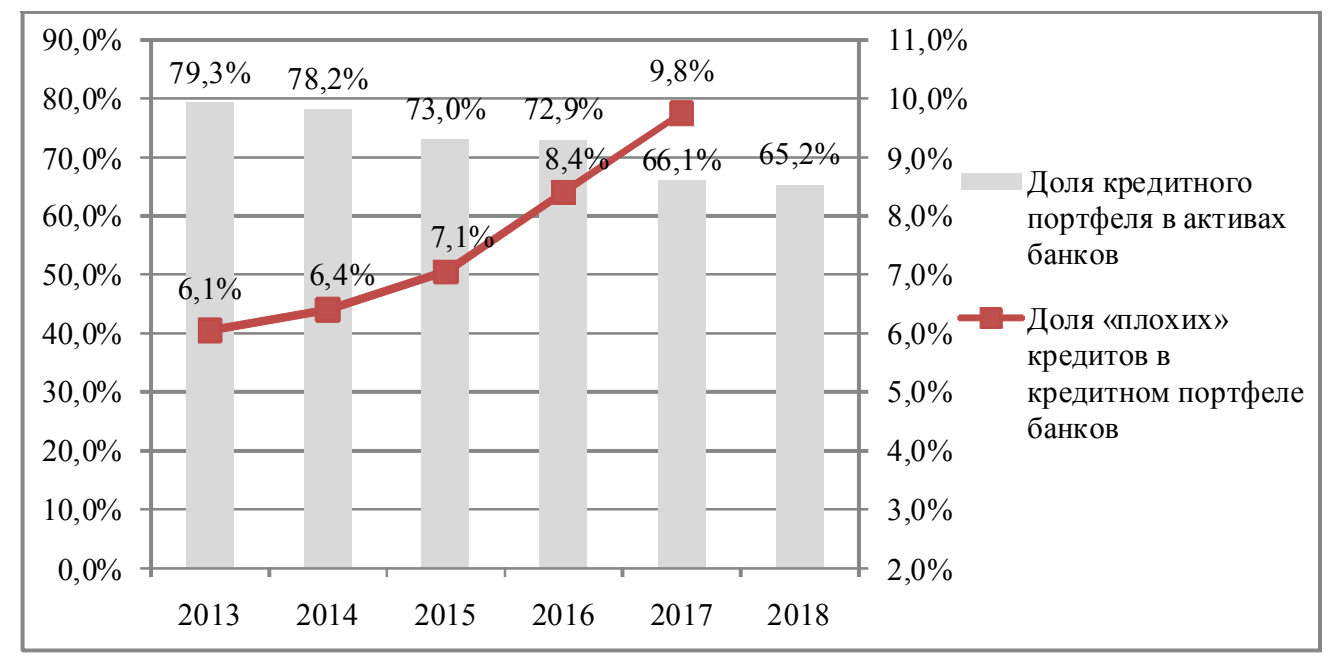

Рис. 9. Доля кредитного портфеля в активах банков и доля «плохих» кредитов в кредитном портфеле банков, \%

Примечание. Составлено авторами по: [Отчет ... в 2015 г.; Отчет ... в 2016 г.; Отчет ... в 2017 г.].

Таблица 3

Показатели рентабельности капитала и активов, степень зависимости банков от межбанковских кредитов и уровень концентрации банковской системы

\begin{tabular}{|c|l|c|c|c|c|c|c|c|}
\hline $\begin{array}{c}\text { № } \\
\text { п/п }\end{array}$ & \multicolumn{1}{|c|}{ Показатель } & $\begin{array}{c}\text { Пороговое } \\
\text { значение }\end{array}$ & 2013 г. & 2014 г. & 2015 г. & 2016 г. & 2017 г. & 2018 г. \\
\hline 1 & $\begin{array}{l}\text { Рентабельность собственного } \\
\text { капитала банков }\end{array}$ & $>15 \%$ & $\begin{array}{c}15,19 \\
\%\end{array}$ & $7,9 \%$ & $2,3 \%$ & $10,3 \%$ & $8,3 \%$ & $13,8 \%$ \\
\hline 2 & Рентабельность активов банков & $>1-2 \%$ & $1,9 \%$ & $0,9 \%$ & $0,3 \%$ & $1,2 \%$ & $1,0 \%$ & $1,5 \%$ \\
\hline 3 & $\begin{array}{l}\text { Нормальный уровень концен- } \\
\text { трации банковской системы }\end{array}$ & $20 / 80$ & $65 \%$ & $73 \%$ & $75 \%$ & $77 \%$ & $79 \%$ & $80 \%$ \\
\hline 4 & $\begin{array}{l}\text { Зависимость банков от межбан- } \\
\text { ковского кредитования }\end{array}$ & $<20-25 \%$ & $8,9 \%$ & $9,3 \%$ & $9,4 \%$ & $10,5 \%$ & $11,5 \%$ & $8,8 \%$ \\
\hline
\end{tabular}

Примечание. Составлено авторами по: [Отчет ... в 2015 г.; Отчет ... в 2016 г.; Отчет ... в 2017 г.; Показатели деятельности ....]. 


\section{ЭКОНОМИЧЕСКАЯ ТЕОРИЯ}

Падение рентабельности собственного капитала и активов банковского сектора объясняется значительным снижением прибыли вплоть до 2016 года. В 2017 г. вновь произошло падение показателей - опять же из-за сокращения прибыльности банковских операций. Подобная ситуация привела к несоблюдению пороговых значений: первый индикатор превышал порог только в 2013 г., а второй - в четырех периодах из шести. Концентрация банковского сектора к концу 2018 г. совпала с предлагаемым в рассматриваемой методике распределением: в этот период на $20 \%$ банков приходилось $80 \%$ активов банковской системы. Последний индикатор не превышал порогового значения в $20-25 \%$, что говорит об отсутствии зависимости российских банков от межбанковского кредитования.

Актуальными индикаторами исследования финансовой безопасности являются ценовые индикаторы, а именно динамика инфляции (рис. 10).

Предложенный авторами порог годовой инфляции - $25 \%$, однако также делается оговорка, что в нормальной экономике развитых и развивающихся по промышленному и постиндустриальному типу стран уровень инфляции составляет 2-5 \% в год. Как видим, годовая инфляция в России в течение последних шести лет не превышала $25 \%$ и в последние годы находилась в пределах, указанных в оговорке. Однако с учетом повышения НДС с 18 до $20 \%$ и цен на бензин и дизельное топливо, произошедшего 1 января 2019 г., ожидается, что инфляция разгонится в текущем году.
Если в 2018 г. месячный прирост цен на товары и услуги не превышал $0,84 \%$, то в январе 2019 г. он уже составил 1,01\%.

\section{Заключение}

Суммируя все вышесказанное, можно отметить, что в экономике России категорически не хватает инвестиций в основной капитал. Более того, в последние годы закредитованность нефинансового сектора экономики держится на достаточно высоком уровне, причем половину этой задолженности составляет краткосрочная. Что касается банковского сектора, то здесь наблюдается перекос пассивов кредитных организаций в сторону краткосрочных привлечений, что ограничивает их возможности по долгосрочному размещению привлеченных средств. Также у банков не прекращается медленный рост «плохих» долгов и имеются проблемы с рентабельностью собственного капитала.

Если мы сравним выявленные проблемы в финансовой сфере экономики России с угрозами, обозначенными в Стратегии экономической безопасности Российской Федерации на период до 2030 г., утвержденной Указом Президента Российской Федерации от 13.05.2017 № 208, то в документе упоминается лишь недостаточный объем инвестиции в реальный сектор экономики и несбалансированность национальной бюджетной системы. В разработанном Минэкономразвития России «Прогнозе долгосрочного социально-экономического развития Российской Федерации на

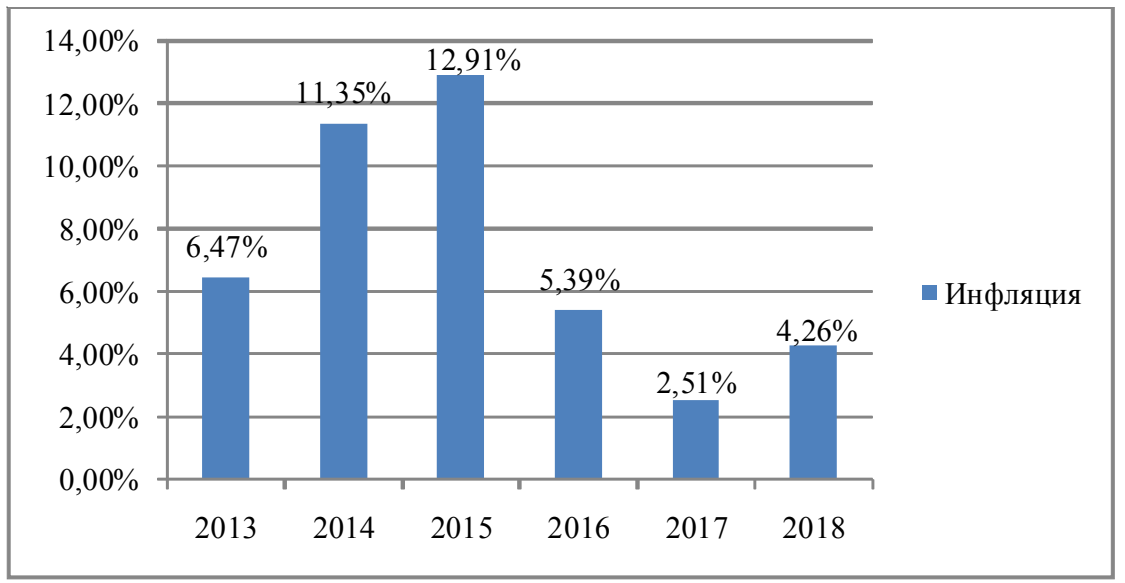

Рис. 10. Динамика инфляции в России, \%

Примечание. Составлено авторами по: [Российский статистический ежегодник, 2018; Цены ...]. 
период до 2030 года» уже приводятся данные по инвестициям в основной капитал, монетизации экономики и задолженности нефинансовых корпораций. Относительно задолженности нефинансовых организаций в документе говорится о повышении их долга перед национальной банковской системой по отношению к ВВП [Прогноз ... до 2030 г.]. Исходя из расчетных данных, мы видим, что по отношению к выручке задолженность нефинансовых корпораций, наоборот, падает с 2015 г., все еще более чем в два раза превышая пороговое значение. Уровень монетизации экономики заметно отстает от прогнозных значений. Так, в прогнозе, даже при самом неблагоприятном сценарии, монетизация в 2015 г. должна была составить $43 \%$, тогда как в действительности она установилась на уровне $37,9 \%$. В 2018 г. она закрепилась на отметке 40,9 \%, поэтому нам видится маловероятным то, что монетизация экономики догонит к 2020 г. прогнозное значение в консервативном сценарии в $48 \%$. Показатель инвестиций в основной капитал к ВВП будет удобнее рассматривать на конкретных цифрах «Прогноза социально-экономического развития Российской Федерации на период до 2036 года», подготовленном Минэкономразвития России. В документе указывается, что при любом сценарии ожидается небольшое падение индикатора до $17 \%$, а затем наметится его постепенное увеличение, что соответствует установившемуся тренду на увеличение инвестиций в основной капитал с 2015 г. [Прогноз ... до 2036 г.].

В целом финансовую безопасность экономики России можно оценить как хорошую. Так, в 2017 г. у большинства показателей отмечалось соблюдение пороговых значений. Однако длительное нахождение за положенными рамками некоторых из индикаторов (отношение инвестиций в основной капитал к ВВП и задолженность нефинансовых организаций) может иметь серьезные последствия в долгосрочной перспективе.

Кроме того, как уже было отмечено, в структуре задолженности нефинансовых организаций более $40 \%$ составляет краткосрочная задолженность, при этом в банках растет процент «плохих» долгов. Из-за большой нагрузки на выручку со стороны общих долгов и процентов по их обслуживанию компаниям может быть нелегко соблюдать платежную дисциплину. Подобная ситуация создает опасность для всего экономического хозяйства страны, поскольку при переходе экономики в стадию спада может вполне возникнуть кризис неплатежеспособности.

Что касается инвестиций в основной капитал: если мы взглянем на структуру использования денежных средств организаций на инвестиционную деятельность, то увидим, что с 2014 по 2017 г. произошло резкое падение доли расходов предприятий на приобретение, создание, модернизацию, реконструкцию и подготовку к использованию внеоборотных активов - с 22,5 до 16,9 \%. Однако в абсолютном выражении инвестиции в данное направление выросли за обозначенный период времени на 19,4 \% [Финансы России, 2018]. Это связано с тем, что все большую часть доходов компании предпочитали тратить на приобретение долговых ценных бумаг и предоставление займов другим лицам, что в 2017 г. составило $66,6 \%$ всех инвестиционных средств. Данное явление можно объяснить желанием организаций финансировать источники, генерирующие стабильный доход на относительно коротких временных промежутках и не требующие крупных организационных затрат. Если рассматривать инвестиции в основной капитал по источникам финансирования, то привлеченные и собственные средства в структуре инвестиций колеблются около $50 \%$ с небольшим перекосом в сторону собственных средств. В относительном выражении бюджетные средства за 2015-2017 гг. занимают все меньшую долю в объеме инвестиций в основной капитал (16,3% на 2017 г.), тогда как в абсолютном выражении они незначительно выросли за данный период [Российский статистический ежегодник, 2018].

В последнее время организации начали переориентировать источники финансирования обновления основного капитала в сторону собственных средств и банковских кредитов, которые выросли в долевом выражении с 50,2 до $51,3 \%$ и с $8,1 \%$ до $11,2 \%$ соответственно. Несмотря на это, основными факторами, сдерживающими инвестиционную деятельность, по-прежнему остаются недостаток собственных средств предприятий, неопределенность экономической ситуации в стране, 
высокий процент коммерческого кредита и инвестиционные риски [Российский статистический ежегодник, 2018].

Рост «плохих» долгов стал одной из центральных проблем банковского сектора в последние годы, потому как еще в 2017 г. данный показатель максимально приблизился к пороговому значению. Во второй половине 2018 г. банк «ФК “Открытие”» по распоряжению Банка России завершил создание Банка непрофильных активов на базе банков «Рост» и «Траст». Мажоритарным акционером Банка непрофильных активов стал Фонд консолидации банковского сектора (97 \%) [Создание банка ...]. Предполагается, что данная организация позволит очистить российский банковский сектор от «плохих» долгов и повысить капитализацию самих банков.

Таким образом, по результатам проведенного исследования можно сделать следующие выводы.

В настоящее время в России соблюдаются пороговые значения по большинству показателей финансовой безопасности. Вместе с тем среди показателей, находящихся за пороговыми значениями, наиболее значимыми являются хронический недостаток инвестиций в обновление основного капитала, закредитованность нефинансовых организаций и рост «плохих» долгов банковского сектора. Нефинансовым организациям требуется более активная бюджетная помощь в сфере финансирования обновления основного капитала в связи с его изношенностью, поскольку им самим не хватает собственных средств для осуществления масштабных инвестиций, а процент коммерческого кредита они находят излишне высоким.

В целях противодействия обозначенным угрозам актуальными направления развития национальной экономики должны стать: расширение инвестиций, включая создание особых льготных условий (и принятие необходимых законов и решений) для крупных прямых инвесторов в импортозамещающие отрасли, которые являются важными с точки зрения безопасности (фармацевтика, медицинское оборудование и др.); повышение доли инвестиций в экономике, в том числе путем увеличения объема государственных инвестиций при повышении ответственности за их эффективное использование; создание национальной и международной (в кооперации с дружественными странами) платежной системы обслуживания банковских карт для исключения критической зависимости от иностранных платежных систем; развитие финансовых центров и институтов для снижения зависимости от доллара и евро.

\section{ПРИМЕЧАНИЕ}

${ }^{1}$ Исследование выполнено при финансовой поддержке РФФИ и Администрации Волгоградской области в рамках научного проекта № 18-410340002 p_а «Совершенствование институционального механизма стимулирования инновационной деятельности как основа экономической безопасности Волгоградской области».

The study was supported by the Russian Foundation for Basic Research (RFBR) and the Volgograd Region Administration in the framework of no. 18-410-340002 p_a "Improvement of the Institutional Mechanism of Stimulating Innovation Activity as the Basis of Economic Security of Volgograd Region" scientific project.

\section{СПИСОК ЛИТЕРАТУРЫ}

Информация по привлеченным кредитными организациями средствам. Объем привлеченных кредитными организациями вкладов (депозитов) физических лиц и объем привлеченных кредитными организациями средств юридических лиц // Банк России. - Электрон. текстовые дан. - Режим доступа: https:/www.cbr.ru/ statistics/?PrtId=pdko_sub. - Загл. с экрана.

Информация по размещенным кредитными организациями средствам. Объем кредитов, депозитов и прочих размещенных средств, предоставленных организациям, физическим лицам и кредитным организациям // Банк России. Электрон. текстовые дан. - Режим доступа: https://www.cbr.ru/statistics/?PrtId=pdko_sub. Загл. с экрана.

Консолидированный бюджет Российской Федерации // Министерство финансов Российской Федерации. - Электрон. текстовые дан. - Режим доступа: https://www.minfin.ru/ru/statistics/ conbud/\#. - Загл. с экрана.

Национальные счета. Валовой внутренний продукт // Федеральная служба государственной статистики. - Электрон. текстовые дан. - Режим доступа: http:/www.gks.ru/wps/wcm/connect/ rosstat_main/rosstat/ru/statistics/accounts/\#. Загл. с экрана. 
Объем государственного внешнего долга Российской Федерации // Министерство финансов Российской Федерации. - Электрон. текстовые дан. - Режим доступа: https://www. minfin.ru/ru/perfomance/public_debt/external/ structure/. - Загл. с экрана.

Объем государственного внутреннего долга Российской Федерации // Министерство финансов Российской Федерации. - Электрон. текстовые дан. - Режим доступа: https://www. minfin.ru/ru/perfomance/public_debt/internal/ structure/total/\#. - Загл. с экрана.

Отчет о развитии банковского сектора и банковского надзора в 2015 году // Банк России. - Электрон. текстовые дан. - Режим доступа: https:// www.cbr.ru/Content/Document/File/48162/ bsr_2015.pdf. - Загл. с экрана.

Отчет о развитии банковского сектора и банковского надзора в 2016 году // Банк России. - Электрон. текстовые дан. - Режим доступа: https:// www.cbr.ru/Content/Document/File/48161/ bsr_2016.pdf. - Загл. с экрана.

Отчет о развитии банковского сектора и банковского надзора в 2017 году // Банк России. - Электрон. текстовые дан. - Режим доступа: https:// www.cbr.ru/Content/Document/File/48160/ bsr_2017.pdf. - Загл. с экрана.

Показатели деятельности кредитных организаций. Показатели деятельности по группам кредитных организаций // Банк России. - Электрон. текстовые дан. - Режим доступа: https:// www.cbr. ru/statistics/?PrtId=pdko_sub. - Загл. с экрана.

Прогноз долгосрочного социально-экономического развития Российской Федерации на период до 2030 года (разработан Минэкономразвития России). - Электрон. текстовые дан. Режим доступа: http://www.consultant.ru/ document/cons doc LAW 144190/. - Загл. с экрана.

Прогноз социально-экономического развития Российской Федерации на период до 2036 года (разработан Минэкономразвития России). Электрон. текстовые дан. - Режим доступа: http://www.consultant.ru/document/cons_doc LAW_312165/.-Загл. с экрана.

Процентные ставки и структура кредитов и депозитов по срочности // Банк России. - Электрон. текстовые дан. - Режим доступа: http:// www.cbr.ru/statistics/?Prtid=int_rat\&ch= PAR_222\#CheckedItem. - Загл. с экрана.

Российский статистический ежегодник. 2018 // Федеральная служба государственной статистики. - Электрон. текстовые дан. - Режим доступа: http://www.gks.ru/free_doc/doc_2018/ year/year18.pdf. - Загл. с экрана.
Сенчагов, В. К. Структура современного мониторинга экономической безопасности России / В. К. Сенчагов, Е. А. Иванов. - М. : Ин-т экономики РАН, 2015. - 46 c.

Создание Банка непрофильных активов завершено // Банк «ФК Открытие». - Электрон. текстовые дан. - Режим доступа: https://www.open. ru/about/press/43808. - Загл. с экрана.

Указ Президента РФ от 13.05.2017 № 208 «О Стратегии экономической безопасности Российской Федерации на период до 2030 года». - Электpoн. текстовые дан. - Режим доступа: http:// www.consultant.ru/document/cons_doc_ LAW_216629/.-Загл. с экрана.

Финансы России. 2016 // Федеральная служба государственной статистики. - Электрон. текстовые дан. - Режим доступа: http:// www.gks.ru/wps/wcm/connect/rosstat_main/ rosstat/ru/statistics/publications/catalog/doc_ 1138717651859. - Загл. с экрана.

Финансы России. 2018 // Федеральная служба государственной статистики. - Электрон. текстовые дан. - Режим доступа: http:// www.gks.ru/wps/wcm/connect/rosstat_main/ rosstat/ru/statistics/publications/catalog/doc 1138717651859. - Загл. с экрана.

Цены. Потребительские цены. Индексы потребительских цен на товары и услуги. На товары и услуги // Федеральная служба государственной статистики. - Электрон. текстовые дан. Режим доступа: http://www.gks.ru/free_doc/ new_site/prices/potr/tab-potr1.htm. - Загл. с экрана.

Экономическая безопасность России. Общий курс : [электрон. учеб.] / под ред. В. К. Сенчагова. 5-е изд. - М. : БИНОМ. Лаборатория знаний, 2015. $-818 \mathrm{c}$.

Gross capital formation (GCF) // The World Bank. Electronic text data. - Mode of access: https:// data.worldbank.org/indicator/NE.GDI.TOTL. CD? end $=2017$ \&locations $=$ RU\&start=2013 . Title from screen.

Gross savings (GS) // The World Bank [Official website]. - Electronic text data. - Mode of access: https://data.worldbank.org/indicator/ NY.GNS.ICTR.CD?end=2017\&locations $=$ RU\&start=2013. - Title from screen.

\section{REFERENCES}

Informacija po privlechennym kreditnymi organizacijami sredstvam. Objem privlechennyh kreditnymi organizacijami vkladov (depozitov) fizicheskih lic i objem privlechennyh kreditnymi organizacijami sredstv juridicheskih lic [Funds borrowed by 
credit institutions. Deposits of individuals accepted by credit institutions and funds of legal entities accepted by credit institutions]. Bank Rossii [Bank of Russia]. URL: https:// www.cbr.ru/statistics/?PrtId=pdko_sub.

Informacija po razmeshhennym kreditnymi organizacijami sredstvam. Objem kreditov, depozitov i prochih razmeshhennyh sredstv, predostavlennyh organizacijam, fizicheskim licam i kreditnym organizacijam [Funds placed by credit institutions. Loans, deposits and other funds extended to organizations, individuals and credit institutions]. Bank Rossii [Bank of Russia]. URL: https://www.cbr.ru/statistics/ ?PrtId=pdko_sub.

Konsolidirovannyj bjudzhet Rossijskoj Federacii [Consolidated budget of the Russian Federation]. Ministerstvo finansov Rossijskoj Federacii [Ministry of Finance of the Russian Federation]. URL: https://www.minfin.ru/ru/ statistics/conbud/\#.

Nacional'nye scheta. Valovoj vnutrennij product [National accounts. Gross domestic product]. Federal'naja sluzhba gosudarstvennoj statistiki [Federal State Statistics Service]. URL: http://www.gks.ru/wps/wcm/connect/rosstat main/rosstat/ru/statistics/accounts/\#.

Objem gosudarstvennogo vneshnego dolga Rossijskoj Federacii [Public external debt of the Russian Federation]. Ministerstvo finansov Rossijskoj Federacii [Ministry of Finance of the Russian Federation]. URL: https://www.minfin. $\mathrm{ru} / \mathrm{ru} /$ perfomance/public_debt/external/ structure/.

Objem gosudarstvennogo vnutrennego dolga Rossijskoj Federacii [Public domestic debt of the Russian Federation]. Ministerstvo finansov Rossijskoj Federacii [Ministry of Finance of the Russian Federation]. URL: https://www.minfin. $\mathrm{ru} / \mathrm{ru} /$ perfomance/public_debt/internal/ structure/total/\#.

Otchet o razvitii bankovskogo sektora i bankovskogo nadzora v 2015 godu [Banking supervision report, 2015]. Bank Rossii [Bank of Russia]. URL: https://www.cbr.ru/Content/Document/File/ 48162/bsr_2015.pdf.

Otchet o razvitii bankovskogo sektora i bankovskogo nadzora v 2016 godu [Banking supervision report, 2016]. Bank Rossii [Bank of Russia]. URL: https://www.cbr.ru/Content/Document/File/ 48161/bsr_2016.pdf.

Otchet o razvitii bankovskogo sektora i bankovskogo nadzora v 2017 godu [Banking supervision report, 2017]. Bank Rossii [Bank of Russia]. URL: https://www.cbr.ru/Content/Document/File/ 48160/bsr_2017.pdf.
Pokazateli dejatel'nosti kreditnyh organizacij. Pokazateli dejatel'nosti po gruppam kreditnyh organizacij [Credit institution performance. Performance indicators by group of credit institutions]. Bank Rossii [Bank of Russia]. URL: https://www.cbr.ru/statistics/?PrtId=pdko_sub.

Prognoz dolgosrochnogo social 'no-jekonomicheskogo razvitija Rossijskoj Federacii na period do 2030 goda (razrabotan Minjekonomrazvitija Rossii) [Forecast of long-term socio-economic development of the Russian Federation for the period up to 2030 (developed by the Ministry of Economic Development of Russia)]. URL: http:// Www.consultant.ru/document/cons_doc_ LAW_144190/.

Prognoz social'no-jekonomicheskogo razvitija Rossijskoj Federacii na period do 2036 goda (razrabotan Minjekonomrazvitija Rossii) [Forecast of socio-economic development of the Russian Federation for the period up to 2036 (developed by the Ministry of Economic Development of Russia)]. URL: http:// www.consultant.ru/document/cons_doc_ LAW_312165/.

Procentnye stavki i struktura kreditov $i$ depozitov po srochnosti [Interest rates and structure of loans and deposits by maturity]. Bank Rossii [Bank of Russia]. URL: http://www.cbr.ru/ statistics/?Prtid=int_rat\&ch=PAR_222\# CheckedItem.

Rossijskij statisticheskij ezhegodnik. 2018 [Russian Statistical Yearbook. 2018]. Federal'naja sluzhba gosudarstvennoj statistiki [Federal State Statistics Service]. URL: http://www.gks.ru/ free_doc/doc_2018/year/year18.pdf.

Senchagov V.K., Ivanov E.A. Struktura sovremennogo monitoringa ekonomicheskoy bezopasnosti Rossii [Structure of Modern Monitoring of Economic Security of Russia]. Moscow, Institut ekonomiki RAN, 2015. 46 p.

Sozdanie Banka neprofil'nyh aktivov zaversheno [Bank of non-core assets ends its creation]. Bank «FK Otkrytie» ["FC Otkritie"Bank]. URL: https:// www.open.ru/about/press/43808.

Ukaz Prezidenta RF ot 13.05.2017 № 208 «O Strategii jekonomicheskoj bezopasnosti Rossijskoj Federacii na period do 2030 goda» [The decree of the President of the Russian Federation as of 13.05.2017 no. 208 “About the strategyof economic security of the Russian Federation for the period up to 2030"]. URL: http://www.consultant.ru/ document/cons_doc_LAW_216629/.

Finansy Rossii. 2016 [Finances of Russia. 2016]. Federal'naja sluzhba gosudarstvennoj statistiki [Federal State Statistics Service]. URL: http:/www.gks.ru/wps/wcm/connect/rosstat_ 
main/rosstat/ru/statistics/publications/catalog/ doc 1138717651859.

Finansy Rossii. 2018 [Finances of Russia. 2018]. Federal'naja sluzhba gosudarstvennoj statistiki [Federal State Statistics Service]. URL: http://www.gks.ru/wps/wcm/connect/rosstat main/rosstat/ru/statistics/publications/catalog/ doc_1138717651859.

Ceny. Potrebitel'skie ceny. Indeksy potrebitel'skih cen na tovary i uslugi. Na tovary i uslugi [Prices. Consumer price index for products and services. Products and services]. Federal'naja sluzhba gosudarstvennoj statistiki [Federal State
Statistics Service]. URL: http://www.gks.ru/ free_doc/new_site/prices/potr/tab-potr1.htm. Senchagov V.K., ed. Jekonomicheskaja bezopasnost' Rossii. Obshhij kurs: [elektron. ucheb.] [Economic security of Russia. General course]. Moscow, BINOM. Laboratorija znanij, 2015. 818 p. Gross capital formation (GCF). The World Bank. URL: https://data.worldbank.org/indicator/ NE.GDI.TOTL.CD?end=2017 \&locations $=$ RU\&start $=2013$.

Gross savings (GS). The World Bank. URL: https://ata. worldbank.org/indicator/NY.GNS.ICTR. CD? end $=2017$ \&locations $=$ RU\& start $=2013$.

\section{Information about the Authors}

Marina E. Buyanova, Doctor of Sciences (Economics), Professor, Head of the Department of Economic Theory, World and Regional Economy, Volgograd State University, Prosp. Universitetsky, 100, 400062 Volgograd, Russian Federation, buyanovam@rambler.ru, https://orcid.org/0000-0003-1052-3780

Yevgeniy S. Rasskazov, Master Student, Volgograd State University, Prosp. Universitetsky, 100, 400062 Volgograd, Russian Federation, rasskazov2016@yandex.ru, https://orcid.org/0000-0002-2015-8919

\section{Информация об авторах}

Марина Эдуардовна Буянова, доктор экономических наук, профессор, заведующий кафедрой экономической теории, мировой и региональной экономики, Волгоградский государственный университет, просп. Университетский, 100, 400062 г. Волгоград, Российская Федерация, buyanovam@rambler.ru, https://orcid.org/0000-0003-1052-3780

Евгений Сергеевич Рассказов, магистрант, Волгоградский государственный университет, просп. Университетский, 100, 400062 г. Волгоград, Российская Федерация, rasskazov2016@yandex.ru, https://orcid.org/0000-0002-2015-8919 